\title{
PENGARUH MODEL PEMBELAJARAN CORE TERHADAP PEMAHAMAN KONSEP PESERTA DIDIK PADA POKOK BAHASAN STRUKTUR ATOM DI KELAS X MIPA SMA NEGERI 1 KAMPAR TIMUR
}

\author{
Siti Aica*, Susilawati, Maria Erna Prodi Pendidikan Kimia FKIP Universitas \\ Riau Email : sitiaicha.as@gmail.com
}

\begin{abstract}
The aim of this research is to know the effect of CORE (Connecting, Organizing, Reflecting and Extending) learning models to students concept understanding of atomic strukture. This research is quasi experimental research with a nonequivalent control group. The population in the research is class X SMA Negeri 1 Kampar Timur. The samples in the research was X MIPA 2 as an experimental class and class X MIPA 5 as a control class which was determined randomly. The experimental class was treated with the implementation of CORE learning model while the control class with a scientific approach. Data was collected using essay test instruments. The data obtained from test were analyzed descriptively and statistically by the test-t right side. The results of data analysis

obtained $t_{\text {count }}=5,63$ and $t_{\text {table }}=1,66$ with $\alpha=0,05, d k=74$. $T_{\text {count }}>t_{\text {table }}$ is $5,63>$ 1,66 meaning that the implementation of CORE learning model can improve

students concept understanding on the subject of atomic structure in the class $\mathrm{X}$ MIPA SMA Negeri 1 Kampar Timur. Criteria students concept understanding in the experimental class with an average $\mathrm{N}$-gain of 0,80 while the average $\mathrm{N}$-gain in the control class is 0,69 .
\end{abstract}

Key Words: CORE learning model, understanding of concepts, atomic structures

\begin{abstract}
Abstrak
Penelitian ini bertujuan untuk mengetahui pengaruh model pembelajaran CORE (Connecting, Organizing, Reflecting and Extending) terhadap pemahaman konsep peserta didik pada pokok bahasan struktur atom. Penelitian ini adalah penelitian quasi experimental dengan desain penelitian nonequivalent control group. Populasi penelitian adalah kelas X SMA Negeri 1 Kampar Timur. Sampel dalam penelitian adalah kelas X MIPA 2 sebagai kelas eksperimen dan kelas X MIPA 5 sebagai kelas kontrol yang ditentukan secara acak. Kelas eksperimen diberi perlakuan dengan penerapan model pembelajaran CORE dan kelas kontrol dengan pendekatan saintifik. Data dikumpulkan dengan menggunakan instrumen tes essai. Data yang didapatkan dari tes dianalisis secara deskriptif dan statistik dengan uji-t pihak kanan. Hasil analisis data diperoleh $t_{\text {hitung }}=5,63$ dan $t_{\text {tabel }}=1,66$ dengan $\alpha$ $=0,05, \mathrm{dk}=74 . \mathrm{t}_{\text {hitung }}>\mathrm{t}_{\text {tabel }}$ yaitu $5,63>1,66$ artinya penerapan model pembelajaran CORE dapat meningkatkan pemahaman konsep peserta didik pada pokok bahasan struktur atom di kelas X MIPA SMA Negeri 1 Kampar Timur.
\end{abstract}


Kriteria pemahaman konsep peserta didik pada kelas eksperimen dengan rata rata $\mathrm{N}$-gain sebesar 0,80 sedangkan rata - rata $\mathrm{N}$-gain pada kelas kontrol sebesar 0,69 .

Kata Kunci: model pembelajaran CORE, pemahaman konsep, struktur atom

\section{PENDAHULUAN}

Pemahaman ilmu kimia yang harus dikuasai oleh peserta didik salah satunya yaitu; pemahaman konseptual. Pemahaman konseptual merupakan pemahaman tentang hal - hal yang berhubungan dengan konsep, yaitu arti, sifat, dan uraian suatu konsep dan juga kemampuan dalam menjelaskan teks, diagram, dan fenomena yang melibatkan konsep - konsep pokok yang bersifat abstrak dan teori - teori dasar sains. (Zidny, 2013).

Kemampuan peserta didik dalam memahami suatu konsep kimia sangat menentukan dalam proses menyelesaikan persoalan kimia. Keberhasilan pembelajaran kimia dapat diukur dari kemampuan peserta didik dalam memahami dan menerapkan konsep dalam mengerjakan soal - soal yang diberikan dengan baik dan benar.

Indikator peserta didik memahami suatu konsep menurut Asep Jihad dan Abdul Haris yaitu: 1) Menyatakan ulang sebuah konsep, 2) Mengklasifikasi obyek - obyek menurut sifat - sifat tertentu (sesuai dengan konsepnya), 3) Menyajikan konsep dalam berbagai bentuk representasi, 4) Menggunakan, memanfaatkan, dan memilih prosedur tertentu, 5) Mengaplikasikan konsep dalam pemecahan masalah.

Materi struktur atom umumnya bersifat teoritis, sehingga menuntut proses berpikir yang lebih dalam agar peserta didik mengerti maksud dari materi yang disampaikan. Struktur atom juga menuntut peserta didik untuk menghafal dan memahami pelajaran. Berdasarkan hasil wawancara dengan salah seorang guru kimia SMA Negeri 1 Kampar Timur diperoleh informasi bahwa pemahaman peserta didik dengan materi kimia masih sangat rendah yang lihat berdasarkan rata - rata nilai ulangan peserta didik pada pokok bahasan Struktur Atom tahun ajaran 2017/2018 tergolong kurang memuaskan yaitu 52 dan persentase ketuntasan peserta didik hanya $27,7 \%$ yang sudah mendapatkan nilai diatas Kriteria 
Ketuntasan Minimum (KKM). Adapun nilai Kriteria Ketuntasan Minimum (KKM) yaitu 65. Hal ini disebabkan rendahnya minat dan pemahaman peserta didik dalam belajar kimia. Untuk itu guru perlu menggunakan suatu model pembelajaran untuk mengaktifkan peserta didik agar ikut berpartisipasi dalam pembelajaran. Upaya yang dapat dilakukan adalah dengan adanya model pembelajaran dapat menarik perhatian peserta didik sehingga memudahkan proses berpikir peserta didik untuk mengerti maksud dari materi yang disampaikan. Model pembelajaran yang dipilih harus dapat memfasilitasi peserta didik dalam mengkonstruksi pengetahuan. Berdasarkan Permendikbud Nomor 103 Tahun 2014 yang menyatakan bahwa peserta didik adalah subjek yang memiliki kemampuan untuk secara aktif mencari, mengolah, mengkonstruksi, dan menggunakan pengetahuan sehingga pembelajaran harus memberikan kesempatan pada peserta didik untuk mengkonstruksi pengetahuan agar benar - benar memahami dan dapat menerapkan pengetahuan. Salah satu model pembelajaran yang dapat meningkatkan pemahaman peserta didik adalah CORE.

CORE merupakan model pembelajaran yang dikembangkan oleh Miller dan Calfee memiliki ciri dan keunggulan yang dapat diterapkan untuk mengatasi permasalahan dalam pembelajaran. CORE merupakan model pembelajaran yang menekankan kemampuan berpikir peserta didik untuk menghubungkan, mengorganisasikan, mendalami, dan mengembangkan informasi yang didapat.

Model pembelajaran CORE terdiri dari empat tahap, yaitu: Connecting, Organizing, Reflecting and Extending. Adapun keempat tahap tersebut akan dijelaskan secara rinci sebagai berikut:

\section{Connecting}

Pada tahap connecting, peserta didik menghubungkan informasi lama dengan informasi baru dan antar konsep. Guru sebagai fasilitator membimbing peserta didik untuk menghubungkan konsep yang berkaitan dengan materi sebelum pembelajaran dengan materi yang akan dipelajari.

2. Organizing

Pada tahap organizing, peserta didik mengorganisasikan informasi informasi yang relevan dengan materi yang dipelajari dan diperoleh dari berbagai 
referensi. Guru membagikan lembar kegiatan organizing kepada peserta didik dan dikerjakan secara individu.

\section{Reflecting}

Pada tahap reflecting, peserta didik menjelaskan atau mengkritik isi dan menyimpulkan dengan bahasa sendiri tentang hasil diskusi. Peserta didik duduk dalam kelompok untuk mendiskusikan jawaban dari lembar organizing yang dilanjutkan dengan presentasi didepan kelas

\section{Extending}

Pada tahap extending, Peserta didik mengembangkan dan memperluas pengetahuan yang mereka peroleh selama proses pembelajaran berlangsung.

Tujuan penelitian ini adalah untuk mengetahui peningkatan pemahaman konsep peserta didik pada materi struktur atom dalam penerapan model pembelajaran CORE (Connecting, Organizing, Reflecting and Extending) di SMA Negeri 1 Kampar Timur.

\section{METODE PENELITIAN}

Penelitian ini merupakan penelitian quasi experimental menggunakan dua kelas yaitu satu kelas eksperimen dan satu kelas kontrol. Desain penelitian menggunakan nonequivalent control group design. Populasi dalam penelitian ini adalah peserta didik kelas X MIPA SMA Negeri 1 Kampar Timur yang terdiri atas tiga kelas yaitu kelas X MIPA 1, X MIPA 2, X MIPA 5. Pengambilan sampel dilakukan dengan teknik simple random sampling dan terpilih kelas X MIPA 2 sebagai kelas eksperimen dan kelas X MIPA 5 sebagai kelas kontrol.

Pemahaman konsep peserta didik diukur dengan menggunakan instrumen tes essai sebanyak 12 soal. Instrumen tes ini sebelumnya telah divalidasi isi oleh dua orang pakar untuk menentukan validitas dan realibilitasnya. Analisis data dilakukan dengan menggunakan $\mathrm{n}$-gain dan uji $-\mathrm{t}$ pihak kanan. Sebelum dilakukan pengujian hipotesis dilakukan uji prasyarat, yaitu: uji normalitas menggunakan uji liliefors, dan uji homogenitas menggunakan uji F. Untuk melihat kriteria peningkatan pemahaman konsep peserta didik dalam proses pembelajaran digunakan n-gain. Nilai n-gain ditentukan melalui persamaan: 


$$
\mathrm{g}=\frac{\text { Spost }- \text { Sprè }}{\text { Smaks }- \text { Spre }}
$$

Hasil perhitungan $\mathrm{N}$ - Gain kemudian diinterpretasikan dengan menggunakan kategori berikut:

Tabel 1. Kategori N - Gain

\begin{tabular}{cc}
\hline Besarnya $\mathrm{g}$ & Kategori \\
\hline $\mathrm{g}>0,7$ & Tinggi \\
$0,3 \leq \mathrm{g} \leq 0,7$ & Sedang \\
$\mathrm{g}<0,3$ & Rendah \\
\hline
\end{tabular}

\section{HASIL DAN PEMBAHASAN}

Hasil penelitian ditinjau dari tiga aspek pengujian yaitu uji normalitas, uji homogenitas, dan uji hipotesis. Hasil uji normalitas dari data nilai sebelum struktur atom untuk kelas X MIPA 1, X MIPA 2, dan X MIPA 5 memiliki $\mathrm{L}_{\text {maks }} \leq$

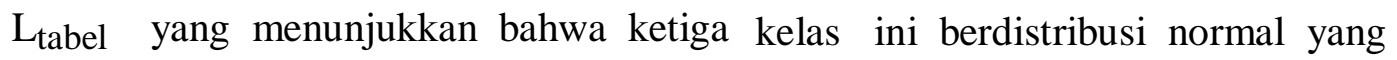
ditunjukkan pada Tabel 2.

Tabel 2. Hasil Analisis Uji Normalitas Data Nilai Sebelum Struktur Atom

\begin{tabular}{ccccccc}
\hline Kelas & $N$ & $\bar{x}$ & $\mathrm{~S}$ & Lmaks & Ltabel & Keterangan \\
\hline MIPA 1 & 38 & 56,77 & 8,40 & 0,10 & 0,14 & \\
MIPA 2 & 38 & 62,69 & 9,75 & 0,09 & 0,14 & Berdistribusi Normal \\
MIPA 5 & 38 & 66,05 & 8,71 & 0,08 & 0,14 & \\
\hline
\end{tabular}

Hasil uji homogenitas dari masing - masing pasangan kelas terlihat bahwa hanya satu pasangan kelas yang homogen yaitu MIPA 2 dan MIPA 5. X MIPA 2 dan $\mathrm{X}$ MIPA 5 mempunyai nilai $\mathrm{F}_{\text {hitung }}<\mathrm{F}_{\text {tabel }}$ yaitu $-0,27<1,76$ dan hasil perhitungan uji-t dua pihak diperoleh nilai $t_{\text {hitung }}$ terletak diantara $-t_{\text {tabel }}$ dan $t_{\text {tabel }}$ $\left(-\mathrm{t}_{\text {tabel }}<\mathrm{t}_{\text {hitung }}<\mathrm{t}_{\text {tabel }}\right)$ yaitu $-1,67<-1,58<1,67$ di tunjukkan pada Tabel 3. Tabel 3. Hasil Analisis Uji Homogenitas Data Nilai Sebelum Struktur Atom

\begin{tabular}{|c|c|c|c|c|c|c|c|}
\hline Kelas & $N$ & $\bar{x}$ & Ftabel & Fhitung & ttabel & thitung & Keterangan \\
\hline \multirow{2}{*}{$\begin{array}{c}\text { MIPA } 1 \\
\text { dan } \\
\text { MIPA } 2\end{array}$} & 38 & 56,7763 & \multirow[b]{2}{*}{1,76} & \multirow[b]{2}{*}{1,35} & \multirow[b]{2}{*}{1,66} & \multirow[b]{2}{*}{$-2,84$} & \multirow[b]{2}{*}{ Tidak Homogen } \\
\hline & 38 & 62,6974 & & & & & \\
\hline \multirow{2}{*}{$\begin{array}{c}\text { MIPA } 1 \\
\text { dan } \\
\text { MIPA } 5\end{array}$} & 38 & 56,7763 & \multirow[b]{2}{*}{1,76} & \multirow[b]{2}{*}{1,08} & \multirow[b]{2}{*}{1,66} & \multirow[b]{2}{*}{$-4,72$} & \multirow[b]{2}{*}{ Tidak Homogen } \\
\hline & 38 & 66,0526 & & & & & \\
\hline \multirow{2}{*}{$\begin{array}{c}\text { MIPA } 2 \\
\text { dan } \\
\text { MIPA } 5\end{array}$} & 38 & 62,6974 & \multirow[b]{2}{*}{1,76} & \multirow[b]{2}{*}{1,25} & \multirow[b]{2}{*}{1,66} & \multirow[b]{2}{*}{$-1,58$} & \multirow[b]{2}{*}{ Homogen } \\
\hline & 38 & 66,0526 & & & & & \\
\hline
\end{tabular}


Hasil uji normalitas nilai pretest dan posttest kelas eksperimen dan kelas kontrol dapat dilihat pada Tabel 4.

Tabel 4. Hasil Analisis Uji Normalitas Data Pretest, Dan Posttest

\begin{tabular}{cccccccc}
\hline Data & Kelas & $N$ & $\bar{x}$ & S & Lmaks & Ltabel & Keterangan \\
\hline \multirow{2}{*}{ Pretest } & MIPA 2 & 38 & 23,5789 & 4,34 & 0,10 & 0,14 & \\
\cline { 2 - 6 } & MIPA 5 & 38 & 24,0263 & 4,25 & 0,09 & 0,14 & \multirow{2}{*}{ Berdistribusi } \\
\multirow{2}{*}{ Posttest } & MIPA 2 & 38 & 85 & 6,83 & 0,10 & 0,14 & Normal \\
\cline { 2 - 6 } & MIPA 5 & 38 & 76,8158 & 5,15 & 0,11 & 0,14 & \\
\hline
\end{tabular}

Hasil analisis data pemahaman konsep peserta didik dapat dilihat pada rata - rata hasil pretest dan posttest.

Tabel 5. Deskripsi Pemahaman Konsep Peserta Didik

\begin{tabular}{ccc}
\multicolumn{2}{c}{ Kelas Eksperimen } & \multicolumn{2}{c}{ Kelas Kontrol } \\
Pretest & Posttest N- N-Gain
\end{tabular}

Gai

\begin{tabular}{lllllll}
\multicolumn{7}{c}{$\mathrm{n}$} \\
\hline $\begin{array}{l}\text { Skor Rata } \\
- \text { Rata }\end{array}$ & 23,58 & 85 & 0,80 & 24,03 & 76,82 & 0,69 \\
\hline
\end{tabular}

Berdasarkan data pada Tabel 6, dapat dilihat bahwa nilai $\mathrm{N}$-gain kelas eksperimen lebih tinggi dari kelas kontrol. Data ini menunjukkan bahwa penerapan model pembelajaran CORE dapat meningkatkan pemahaman konsep peserta didik.

Tabel 6. Hasil Analisis Uji Hipotesis

\begin{tabular}{lccccccc}
\hline \multicolumn{1}{c}{ Kelas } & $N$ & $\bar{x}$ & $\mathrm{~S}$ & $\mathrm{~S}_{\text {gab }}$ & thitung & tabel & Keterangan \\
\hline Ekperimen & 38 & 61,42 & 7,34 & & & & \\
Kontrol & 38 & 52,79 & 5,87 & 6,68 & 5,63 & 1,66 & Diterima \\
\hline
\end{tabular}

Uji hipotesis dilakukan dengan menguji $H_{l}$ dengan menggunakan uji - t pihak kanan, hasil uji hipotesis thitung $=5,63$ dan nilai tabel pada $\alpha=0,05$ dengan $\mathrm{dk}$

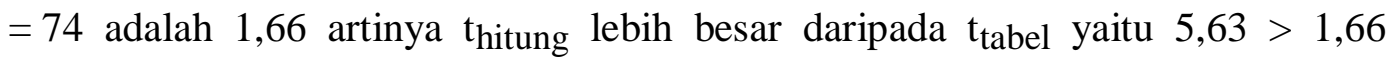
sehingga $H_{1}$ diterima, artinya peningkatan pemahaman konsep peserta didik dengan penerapan model pembelelajaran CORE (Connecting, Organizing, Reflecting and Extending) dapat diterima. 
Penerapan model pembelajaran CORE dalam penelitian yang telah dilakukan, pada kelas eksperimen yaitu kelas X MIPA 2 di SMA Negeri 1 Kampar Timur membuat peserta didik lebih cepat dalam memahami materi struktur atom yang dipelajari, dilihat pada saat berlangsungnya proses pembelajaran. Berdasarkan penelitian yang telah dilakukan model CORE dapat meningkatkan pemahaman konsep peserta didik. Hal ini telah dibuktikan menggunakan perhitungan statistik yaitu uji $t$ dengan $t_{\text {hitung }}>t_{\text {tabel }}$ dengan nilai $t_{\text {hitung }}=5,63$ dan $t_{\text {tabel }}=1,66$, dan kriteria peningkatan pemahaman konsep peserta didik termasuk kategori tinggi. Peserta didik dikatakan memahami sesuatu apabila Ia dapat memberikan penjelasan atau memberi uraian yang lebih rinci tentang suatu hal dengan menggunakan kata - kata sendiri (Sudijono, 2009).

Penerapan model pembelajaran CORE dalam penelitian yang telah dilakukan, selain dapat menjadikan peserta didik lebih memahami materi, peserta didik aktif dalam bertanya, menjawab, dan berkomunikasi pada saat diskusi. Aktifitas peserta didik dalam proses pembelajaran struktur atom dapat dilihat dalam setiap tahap pada model pembelajaran CORE (Connecting, Organizing, Reflecting and Extending).

Tahap Connecting, guru membimbing peserta didik untuk menghubungkan konsep yang berkaitan pada sub pokok bahasan kimia dan peranannya dengan sub pokok bahasan perkembangan model atom "Pada pertemuan sebelumnya kita mempelajari tentang materi dan klasifikasinya. Jika kita perhatikan di alam ini, terdapat begitu banyak jenis materi. Tahukah anda, bahwa semua jenis materi tersebut sebenarnya memiliki satu kesamaan? Ya, semua materi tersusun atas partikel - partikel kecil yang disebut atom" Hal ini dijadikan modal pertama peserta didik dalam pembelajaran. Adanya kemampuan peserta didik untuk menghubungkan antar konsep dapat mengakibatkan pemahaman peserta didik tentang konsep - konsep akan lebih luas dan mendalam. Sesuai dengan pendapat Dahar (2011) yang mengungkapkan bahwa faktor yang paling mempengaruhi belajar adalah pengetahuan awal peserta didik sehingga pelajaran yang baru dapat diadaptasi dengan pengetahuan yang telah dimiliki. 
Tahap Organizing, guru membagikan lembar kegiatan organizing kepada peserta didik dan dikerjakan secara individu. Peserta didik diminta untuk menceritakan kembali proses perkembangan teori atom. Kemampuan peserta didik dalam mengorganisasikan pelajaran dan mengatur informasi yang telah mereka dapatkan, hal inilah yang nantinya dapat meningkatkan kemampuan penalaran peserta didik. Kegiatan organizing merupakan tahap yang sangat penting. Sesuai dengan pendapat Miller dan Calfee (2004) tahap mengorganisasi informasi tidak hanya bertujuan agar peserta didik dapat mengorganisasi konsep konsep sebelum dan selama proses pengumpulan informasi itu terjadi tetapi juga bertujuan agar peserta didik dapat menggunakan kembali pada tahap selanjutnya.

Tahap Reflecting, guru membagi peserta didik ke dalam 8 kelompok, setiap kelompok ditugaskan untuk mendiskusikan jawaban dari lembar organizing. Peserta didik merefleksikan jawaban dari lembar organizing dan mempresentasikan hasil diskusinya didepan kelas. Tahap inilah yang digunakan oleh guru sebagai penengah untuk meluruskan kesalahan yang dilakukan peserta didik.

Tahap Ekstending, guru membagikan LKPD kepada peserta didik dikerjakan secara individu dalam kelompok. Pada tahap ini guru memberikan kesempatan kepada peserta didik untuk memperluas pengetahuannya. Sesuai dengan pendapat Suyatno (2009) yaitu tahap ekstending merupakan tahap dimana peserta didik dapat memperluas pengetahuan yang sudah diperoleh selama proses pembelajaran berlangsung.

Hasil penelitian menunjukkan bahwa nilai rata - rata kelas eksperimen lebih tinggi dibandingkan dengan nilai rata - rata kelas kontrol. Hal ini disebabkan oleh peran aktif dari peserta didik dan kemampuan berpikir dari peserta didik untuk menghubungkan, mengorganisasikan, mendalami, dan mengembangkan informasi yang didapat. Sesuai dengan pendapat Slameto (2010), yang menyatakan bahwa bila peserta didik telah berpartisipasi aktif dalam pembelajaran maka peserta didik akan memiliki pengetahuan atau pemahaman mengenai materi pelajaran dengan baik, apabila peserta didik telah memahami dan memiliki pengetahuan terhadap materi akan mempermudah peserta didik dalam 
mengerjakan soal dan tugas yang mengakibatkan peningkatan prestasi belajar peserta didik.

\section{KESIMPULAN}

Penerapan model pembelajaran CORE dapat meningkatkan pemahaman konsep peserta didik pada pokok bahasan struktur atom di kelas X MIPA SMA Negeri 1 Kampar Timur dan peningkatan pemahaman konsep peserta didik dengan menerapkan model pembelajaran CORE berada pada kategori tinggi.

\section{DAFTAR PUSTAKA}

Calfee, R. C, Curwen, M. S, Miller, R. G, White-Smith, K. A. 2010. Increasing Teachers Metacognition Develops Students Higher Learning During Content Area Literacy Instruction : Findings From The Red - Write Cycle Project. Issues In Teacher Education, 19 (2).

Dahar, R. W., 2011, Teori Belajar dan Pembelajaran, Erlangga, Jakarta.

Jihad, A. dan Haris, A., 2009, Evaluasi Pembelajaran, Multi Presindo, Jakarta.

Kemendikbud, 2014, Lampiran Peraturan Menteri Pendidikan dan Kebudayaan RI Nomor 103 Tahun 2014 tentang Pembelajaran Pada Pendidikan Dasar dan Pendidikan Menengah, Kemendikbud, Jakarta.

Meltzer, D. T., 2002, The Relationship Between Mathematics Preparation And Conseptual Learning Gains In Physics : A Possible "Hidden Variable "In Diagnostic Pretest Score, Departement Of Physics And Astronomy, Iowa State University Ames, Iowa 50011.

Miller, R. G and Calfee, R. C, 2004, Making Thinking Visible : A Method To Encourage Science Writing In Upper Elementary Grades, Science and Children, 42 (3).

Slameto, 2010, Belajar dan Faktor Yang Mempengaruhinya, PT. Rineka Cipta, Jakarta.

Suyanto, 2009, Menjelajah Pembelajaran Inovatif, Masmedia Buana Pustaka, Sidoarjo.

Sudijono, A., 2009, Pengantar Statistik Pendidikan, Rajawali Pers, Jakarta.

Zidny, R., 2013, Analisis Pemahaman Konsep Siswa SMA Kelas X Pada Materi Persamaan Kimia Dan Stoikiometri Melalui Penggunaan Diagram Submikroskopik SertaHubungannya Dengan Kemampuan Pemecahan Masalah, Jurnal Riset dan Praktik Pendidikan Kimia, 1 (1). 